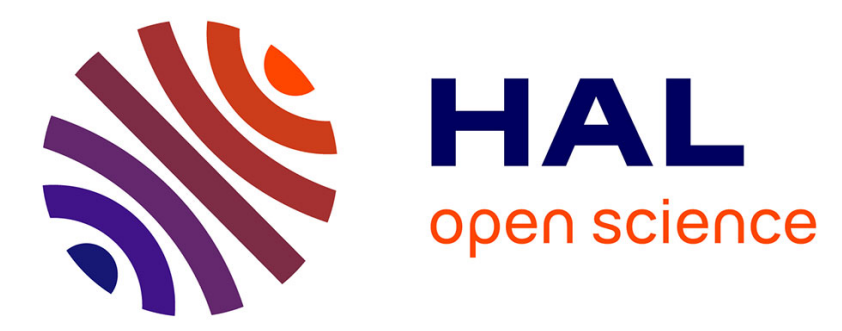

\title{
Differences in technology transfer between science-based and development based industries: transfer mechanisms and barriers
}

Victor Gilsing, Rudi Bekkers, Bodas Isabel Maria Freitas, Marianne van Der Steen

\section{To cite this version:}

Victor Gilsing, Rudi Bekkers, Bodas Isabel Maria Freitas, Marianne van Der Steen. Differences in technology transfer between science-based and development based industries: transfer mechanisms and barriers. Technovation, 2011, 31 (12), pp.638-647. 10.1016/j.technovation.2011.06.009 . hal01487500

\section{HAL Id: hal-01487500 \\ http://hal.grenoble-em.com/hal-01487500}

Submitted on 12 Mar 2017

HAL is a multi-disciplinary open access archive for the deposit and dissemination of scientific research documents, whether they are published or not. The documents may come from teaching and research institutions in France or abroad, or from public or private research centers.
L'archive ouverte pluridisciplinaire HAL, est destinée au dépôt et à la diffusion de documents scientifiques de niveau recherche, publiés ou non, émanant des établissements d'enseignement et de recherche français ou étrangers, des laboratoires publics ou privés. 
Cite as: "Gilsing V.; Bekkers, R.; Bodas Freitas, I. M. and Van der Steen, M. (2011). Technology Transfer between Academia and Industry: Do policies fit with standing practices? Empirical evidence from the Netherlands. Technovation, 31(12), 638-647."

\title{
Differences in technology transfer between science-based and development- based industries: transfer mechanisms and barriers
}

Gilsing V.; Bekkers, R.; Bodas Freitas, I. M. and Van der Steen, M.

\begin{abstract}
Although several studies in the wide body of literature on technology transfer have hinted at differences across industries, this still remains an understudied issue. Our study addresses this topic and considers to what degree technology transfer processes differ across different industrial sectors. To that end, we study to what extent technology transfer processes differ along both types of transfer mechanisms and key barriers inhibiting the transfer process. Based on a survey of Dutch practitioners on both sides of the transfer process, we test a number of hypotheses that differentiate between science-based regimes and developmentbased regimes. While our findings confirm our hypotheses concerning differences between the regimes regarding the use of specific transfer mechanisms, we also find that both regimes share a number of mechanisms that are similar. In addition, our findings show a remarkable degree of similarity among barriers inhibiting the process. We discuss these findings within the context of the broader literature and formulate policy implications.
\end{abstract}

Key-words: university-industry technology transfer, technology transfer mechanisms, technology transfer barriers 


\section{Introduction}

In the vast and rapidly developing literature on technology transfer, there is a growing understanding of its multifaceted nature. It has been demonstrated how the transfer of technological knowledge from academia to industry is affected by a wide range of factors, such as type of transfer mechanisms employed (Cohen et al., 2002; Balconi and Laboranti, 2006; Giuri et al., 2007), the role of (regional) clusters (e.g. Porter, 1990) as well as national legislation like the Bayh-Dole Act (Berman, 2008; Kenney and Patton, 2009). These useful insights notwithstanding, an under-addressed issue remains in how far technology transfer processes are homogeneous across different industries, or more heterogeneous instead. Although some literature has stressed the differentiated nature of the contribution of academic research to industrial innovation (Breschi et al, 2000; Marsili, 2001), we still know little about the extent to which technology transfer processes differ across industrial sectors, and whether these differences are rather substantial or only minor. In this paper, these differences form the central theme.

In the recent literature, there are two streams of research suggesting that technology transfer processes do differ across industries. The first stream suggests that differences apply especially to the use of certain types of transfer mechanisms relative to others (e.g. Bonaccorsi and Piccaluga, 1994; D'Este and Patel, 2007; Bekkers and BodasFreitas, 2008; Yusuf, 2008), such as the use of more formal mechanisms (e.g. licenses, patents or contracts) versus more informal mechanisms (e.g. personal contacts between academics and industrial researchers). In this literature the primary focus is on differences between types of transfer mechanisms facilitating knowledge flows between academia and industry. The second strand of literature is more concerned with the role of impeding factors in the transfer process and the potential role of public policy in addressing these factors. Although various studies have demonstrated that policy may contribute to improving knowledge exchange between 
academia and industry (Rasmussen, 2008; Bercovitz and Feldman, 2006; Peneder, 2008; Krabel and Mueller, 2009), there have also been concerns that such policies may ignore the presumed diversity in different university-industry technology transfer activities and in barriers impeding the process (e.g. Azagra-Caro, 2007; Boardman, 2008; Boardman and Ponomariov, 2009).

Despite their different emphasis, both strands of literature share a focus on the differences between technology transfer processes whereas they leave unexplained in how far such differences are either very substantial or, alternatively, quite limited. Nor do they reveal how much technology transfer processes may possibly have in common. The purpose of this paper is to address these issues. To accomplish this, we make an explicit distinction between the role of technology transfer mechanisms (i.e. an instrument or a channel through which knowledge can flow from academia to industry; see below) and barriers in the transfer process (i.e. factors that may affect the functioning of mechanisms and inhibit the flow of knowledge from academia to industry). Following this distinction, we address the following two key questions. First, in how far do technology transfer processes differ regarding the dominant technology transfer mechanisms employed? Second, in how far do technology transfer processes differ regarding barriers inhibiting the transfer process? By addressing these questions, we can assess in how far technology transfer processes may possibly differ in one respect (e.g. type mechanisms) but may still be rather similar in the other way (e.g. barriers), or vice versa.

In this way, we contribute to the literature by elucidating to what extent technology transfer processes differ across industries regarding either the use of transfer mechanisms, barriers or possibly both. Whereas recent empirical studies have only considered technology transfer from either the perspective of industry (Cohen et al., 2002; Fontana et al., 2006) or from the perspective of academia (DiGregorio and Shane, 2003; Calderini et al., 2007), our study is 
different in that we consider both sides of the transfer process. A second contribution is that we develop a more comprehensive view regarding the types of transfer mechanisms being used. We not only consider the role of formal mechanisms that especially facilitate the transfer of codified knowledge, as most prevalent in the literature until now (D'Este and Patel, 2007), but also include the role of informal mechanisms that are more relevant for the transfer of tacit knowledge (Ponomariov and Boardman, 2008; Cohen et al., 2002). In addition, we consider both more 'passive' mechanisms that tend to be more one-directional (e.g. scientific publications, patent texts), and also more 'active' mechanisms enabling more bidirectional knowledge flows (e.g. temporary staff exchange) that have also been neglected until now (D'Este and Patel, 2007). This paper is structured as follows. Section 2 describes the development of a theoretical framework that discriminates between two types of technology transfer regimes. Section 3 introduces the survey among academic and industrial researchers, which we used to test our hypotheses. Section 4 discusses the empirical findings and relates them to the hypotheses. Finally, in section 5, we discuss our findings within the context of the broader literature, draw conclusions and discuss policy implications.

\section{Conceptual framework and hypotheses: two regimes of technology transfer}

As a basis for our theoretical framework, we start from the idea by Nelson and Winter (1982) that the nature of technological knowledge affects its transfer and exchange between innovating agents. Based on this, these authors differentiate between a so-called more 'entrepreneurial' regime and a more 'routinized' regime in order to understand the variety of innovation processes observed across industrial sectors. An 'entrepreneurial' regime is characterized by science-based technology in which the knowledge base is non-cumulative and universal. In contrast, a 'routinized' regime is characterized by more cumulative technological knowledge that is specific to industrial applications (Nelson and Winter, 1982). 
These profound differences in the nature of technological knowledge underlying both regimes may also carry some important implications for technology transfer practices between science and industry (Breschi et al., 2000). To specify this further, we build on Pavitt's original taxonomy (1984) and on later work by Marsili (2001) and Marsili and Verspagen (2002) to examine to what extent technology transfer processes between academia and industry differ across industrial sectors. Table 1 shows the basic differences between both types of technological transfer regimes. Here, we distinguish between (A) key characteristics of scientific knowledge and its importance to industry, and (B) key characteristics of the transfer process. Below we provide a brief description of the five dimensions.

[Table 1 about here]

(1) Differentiation of the knowledge base points to the extent to which knowledge is stand-alone or systemic. Teece (1986) defines knowledge as stand-alone when it can be considered as (relatively) independent from other knowledge. In contrast, knowledge is systemic when its development or application requires integration with other pieces of knowledge, which may stem from different scientific and/or engineering disciplines, thus forming part of a larger system.

(2) The nature of scientific knowledge indicates whether knowledge is more generic and broad or more specific and specialized (Breschi et al., 2000). In the first case, it is formed by more fundamental, scientific knowledge that represents state-of-the-art advances in basic science, often referred to as 'basic knowledge'. Alternatively, it can also be formed by more specific, practically oriented knowledge, often referred to as 'applied knowledge'.

(3) The two regimes also differ in terms of the importance of scientific knowledge. Obviously, in a science-based regime, scientific knowledge is relatively more important and 
its impact is relatively larger and more direct (Marsili, 2001). In contrast, in a developmentbased regime, its importance is relatively lower and complemented by other sources of technological knowledge such as collaboration with users, suppliers, competitors, consultants and so on (Marsili, 2001).

(4) Both regimes also differ in terms of the intensity of interaction. Given the nature of technological knowledge, a science-based regime may be characterized by a more limited degree of interaction between science and industry, when compared to a developmentoriented regime. The latter tends to be characterized by rather frequent contact and more durable collaboration, in some cases covering many years (Balconi and Laboranti, 2006). (5) In this paper, we take a comprehensive approach to the diversity of mechanisms employed for the transfer of technology. As already mentioned, we include both 'active' mechanisms and more 'passive' mechanisms (e.g. publications). After all, publications have consistently been found to be among the most important ways for knowledge transfer (Cohen et al., 2002; Arundel et al., 1995; Salter and Martin, 2001). In addition, we consider both more 'passive' mechanisms that tend to be more one-directional and more 'active' mechanisms enabling more bidirectional knowledge flows (D'Este and Patel, 2007). Based on this taxonomy, we formulate a number of hypotheses that specify the relative differences between both regimes regarding transfer mechanisms (section 2.1) and key barriers (section 2.2).

\subsection{Key transfer mechanisms: relative differences between regimes}

\section{Science-based regime}

This regime is characterized by a relatively strong dependency of industry on external sources of knowledge such as universities, public research institutes and research-intensive firms (Pavitt 1984; Coriat and Weinstein, 2001; Marsili, 2001; Nikulainen and Palmberg, 2010). This contribution of academic research is large and entails (highly) scientific, basic 
knowledge. Knowledge inputs into the search processes are often formed by publicly available, scientific knowledge, which is then transformed through the use of formal scientific principles and methods into newly created knowledge. Most of this newly generated knowledge is expressed in written documents and is made available through publications, research proceedings, reports and patent descriptions. As such, the outcome of this search process is highly codified (McMillan et al., 2000; Cohen et al., 2002). This knowledge is based on a limited number of technological fields (Coriat and Weinstein, 2001; Coriat et al., 2003), which reflects the relatively stand-alone nature of the as indicated by its low level of differentiation (Marsili, 2001). Examples of technology transfer with a science-based regime include, among others, those in pharmaceuticals and chemicals. These fields benefit mostly from scientific advances in biology, chemical engineering, chemistry and medical science (Marsili, 2001).

Firms develop new technology based on a combination of (formal) in-house R\&D and collaboration with (public) research institutes, as well as with small firms specialised in relevant fields (Coriat and Weinstein, 2001). There tends to be a division of labour between these organizations: academia specialises in basic research whereas firms specialise in applied research. Nevertheless, in-house R\&D must be at the leading edge in order to create and maintain sufficient absorptive capacity in view of cooperating with specialised research institutes (Cohen and Levinthal, 1990; Fontana et al., 2006). In this way, (highly) codified knowledge flows from academia to industry, implying that mechanisms that especially facilitate the transfer of this codified knowledge will be relatively more important than a development-based regime. Still, the transfer process itself is also characterized by trial and error, especially when firms actively participate in scientific research. As a consequence, also informal mechanisms, R\&D collaboration and consultancy by academic staff that facilitate the transfer of more tacit knowledge are of importance in the transfer process (D'Este and 
Patel, 2007). Another key mechanism for the transfer of both codified and tacit knowledge components is formed by spinoffs. Academic spin-offs form an effective vehicle to exploit radical, early-stage technologies. It has the capacity to exploit the codified outcomes by combining and integrating them with the tacit knowledge of the inventors (as founders), which is required for the further development of the new technology (Koumpis and Pavitt, 1999; Gilsing et al., 2010).

\section{Development-based regime}

Compared to the previous regime, the development-based regime is characterized by a lower degree of (direct) dependency of industry on academic sources of knowledge. Although external sources of knowledge can play a considerable role for firms in this regime, these are often non-academic and can be formed by bridging institutions, suppliers, (lead) users, consultants and so on (Coriat and Weinstein, 2001; Marsili, 2001). In this way, the contribution of academia occurs more indirectly way as knowledge transfer to firms can take place through these parties (Martin, 1998; Swann, 2002). In cases where it contributes directly, it entails more applied knowledge and tends to be relatively more systemic as indicated by its higher degree of differentiation (Marsili, 2001). This systemic nature makes that no single type of actor disposes over all relevant pieces of knowledge, indicating that academia forms part of a portfolio of external knowledge sources from the perspective of firms. Examples of more engineering-oriented industries include, among others, instruments, electrical-electronic products, and motor vehicles, al of which benefit mostly from academic research in mechanical and electrical engineering, computer science, and mathematics (Marsili, 2001).

The relatively more systemic nature of knowledge creates a need for firms to integrate different yet related technological fields and here a rather intensive interaction between 
academia and firms may accommodate this integration process (Coriat and Weinstein, 2001). Compared to the science-based regime, the transfer process in a development-based regime has more bi-directional knowledge flows between academia and industry (Coriat and Weinstein, 2001). As a consequence, transfer of technology depends more on mechanisms that support this need for a higher intensity of interaction such as joint R\&D projects, participation in conferences and/or workshops, regional and/or professional networks as well as inflow of $\mathrm{PhD}$ graduates (Cohen et al., 2002). Codified knowledge such as publications and patent texts remain a key source, but not to the extent as in a science-based regime.

Based on the above, we formulate two hypotheses that specify the relative importance of a number of key transfer mechanisms as employed in a science-based regime as compared with a development-based regime, and vice versa.

Hypothesis 1: Scientific publications, patent data and academic spin-offs are more important means of technology transfer in science-based regimes than in development-based regimes.

Hypothesis 2: Joint R\&D collaborations, participation in conferences and in regional and/or professional networks, as well as inflow of PhD graduates are more important means of technology transfer in development-based regimes than in science-based regimes.

\subsection{Barriers inhibiting technology transfer}

In this section we discuss barriers that may inhibit technology transfer. We distinguish between barriers that are expected to be similar for both regimes and barriers that differ.

Barriers that are similar for both a science-based and development-based regime

An initial barrier may arise due to the risk of information leakage. Especially in the context of research collaboration or contract research, there is a general risk of information leakage to 
partners and/or competitors, also referred to as (undesirable) spill-overs (Gilsing and Nooteboom, 2006). This risk of information leakage is especially a concern for firms, and is supposedly greater when they collaborate with academia than when collaborating with other firms. Although knowledge spill-overs to universities may not so much lead to acts of freeridership as such, the more fundamental problem is that universities may use this knowledge to develop new inventions that they will subsequently (want to) disclose. In this way, specific knowledge held by a firm may spill over to a much larger network than would be the case in an alliance with one or two commercial partners where exclusivity can be effectively agreed upon (Lin et al., 2009). Instead, universities have the (regulatory) obligation to disseminate new technological knowledge as widely as possible. In other words, collaboration with universities may amplify the risk of information leakage to a considerable extent. Consequently, rather than engaging in collaboration with academia, firms may decide to avoid it altogether (Gilsing and Nooteboom, 2006). Therefore, the risk of information leakage forms a barrier as it may inhibit firms from engaging in technology transfer in the first place. A second barrier may arise from the risk of a conflict of interests. Firms and universities are exposed to different incentive schemes that shape their interests in the transfer process. For firms it is especially important to appropriate new technological knowledge in order to create a competitive advantage and ensure rapid commercialisation (Teece, 1986). For universities it is most important to contribute to the public knowledge domain by means of rapid dissemination, especially through publications and conferences. This contributes to their reputation and academic visibility (DiGregorio and Shane, 2003). As a consequence, these different incentive schemes carry a risk of a conflict of interests once firms and universities agree on collaboration or interaction for technology transfer. A third barrier is formed by scientific knowledge being too general to be useful for firms. For scientific knowledge to be useful to firms, it is crucial that it meets (very) specific knowledge 
needs that cannot be fulfilled by other knowledge inputs, such as those from external sources such as suppliers, customers, competitors, new ventures, consultants, etc. (Marsili, 2001). The more general the nature of knowledge, the more likely it is to overlap with knowledge than can be obtained from such other sources, reducing its usefulness to firms (Vanhaverbeke et al., 2009). On the basis of the above, our third barrier inhibiting the transfer process is constituted by scientific knowledge being too general in nature and lacking sufficient specificity to address a firm's specialised knowledge needs. Overall, this suggests the following hypotheses specifying three general barriers that can occur in both a science-based regime and a development-based regime.

Hypothesis 3a: In both regimes, a major barrier is formed by a risk of information leakage.

Hypothesis 3b: In both regimes, a major barrier is formed by a risk of conflict of interests.

Hypothesis 3c: In both regimes, a major barrier is formed by scientific knowledge being too general.

Barriers that are different for science-based regimes and for development-based regimes As discussed in section 2.1, a science-based regime tends to be characterized by some division of labour because academia specialises in basic research whereas firms specialise mostly in applied research. At the same time, in-house R\&D at firms must be at the leading edge in order to create and maintain sufficient absorptive capacity in view of cooperating with specialised research institutes (Cohen and Levinthal, 1990; Fontana et al., 2006). Accomplishing the latter may carry high costs for firms in order to stay up-to-date and to manage collaborative projects in such a way that new, state-of-the-art knowledge can be effectively integrated with their own internal knowledge base. These high costs for knowledge absorption within its organization may form a barrier. This barrier is more likely to inhibit the transfer process in a science-based regime, when compared to a development-based regime. 
Because in a science-based regime there is a high(er) necessity for firms to invest in costly basic research in order to create and maintain sufficient absorptive capacity to be able to deal

with state-of-the-art, scientific knowledge from academia.

As discussed in section 2.1, a development-based regime tends to be characterized by comparatively lower (direct) dependency of industry on academic sources of knowledge because the major emphasis lies on the role of applied knowledge (Marsili, 2001). In this regime, therefore, academic knowledge may easily become too theoretical for firms to be useful to foresee in their application-oriented knowledge needs. As a consequence, academic knowledge being too theoretical may form a barrier that is more likely to occur in a development-based regime. Based on the above, we formulate our hypotheses that specify relative differences between a science-based regime versus a development-based regime, regarding specific barriers inhibiting the process.

Hypothesis 4a: High costs of managing joint research projects are more a barrier in a science-based regime than in a development-based regime.

Hypothesis 4b: Knowledge being too theoretical for a firm is more a barrier in a development-based regime than in a science-based regime.

\section{Data and methodology}

For our empirical approach, we relied on input from university and industry practitioners and considered what they actually use in their daily practices (e.g. Welsh et al., 2008). This is in line with recent suggestions in the literature not to rely on Technology Transfer Offices (TTO) data or patent data nor on best practices from the biotechnology sector. Instead, when collecting our data, we have adopted such a practitioners' perspective and studied what the actual developers and users of knowledge perceive as key mechanisms and barriers. To accomplish this, two related questionnaires were developed that were sent to actual academic 
and industry researchers, rather than to their seniors or managers or to TTO staff. We are conscious of the fact that we are sometimes measuring perceptions here, and that there may be intersubjectivity in interpreting questions and concepts (cf. Boardman and Ponomariov, 2009). At the same tine, however, we also note that these individuals are the practitioners and hence directly involved in the transfer process through personal contacts, by studying the literature, attending conferences, holding dual positions, and so on.

Given potential cultural differences in behaviour and/or the impact of national policies, we have chosen to collect our data in one single country. Because of our knowledge of the local institutional environment, we chose The Netherlands. In The Netherlands, public policy from about 2000 onwards has strongly encouraged both universities and firms to become more active in technology transfer. Although this policy stresses the importance of technology transfer in general, it has not focused on one or more specific transfer mechanisms in particular. While this Dutch policy approach might have increased overall levels of technology transfer, we have no reasons to expect that relative differences between mechanisms and/or between regimes were affected. At the same time, we recognise that each country has its specific contextual features relating to its university system, and the Netherlands form no exception to that. While it is beyond the scope of this paper to present a fully international comparison, we would like to note a few examples. First, Dutch institutions encourage their staff to transfer their knowledge to industry, by considering such activities as also forming part of their job responsibility. Such encouragement includes basically all possible mechanisms to transfer knowledge, though. Second, Dutch institutions generally allow staff to work part-time in industry, which is also common in some other countries such as the US (Boardman and Ponomariov, 2009). Third, The Netherlands have no legislation comparable to the Bayh-Dole Act. The Bay-Dole Act entails a legal obligation for universities to install disclosure procedures regarding their inventions, to report publicly on their 
university patents and to be actively engaged in research commercialisation. In the Netherlands such legal obligations do not exist, leaving it to the individual universities whether (and how) they engage herein or not (Bekkers et al., 2006). Such national aspects may affect the degree to which our results could be generalized to other countries, an issue we will come back to in our concluding section.

Our survey was conducted in 2006 in The Netherlands and the questionnaires are available from the internet at [removed for the reviewing process]. One key measurement was the actual use and the importance of 24 different mechanisms of technology transfer (following Cohen et al., 2002 or D'Este and Patel, 2007). Note that respondents could only rate the actual importance of specific mechanisms if they actually used them. The other key measurement was on the barriers for technology transfer.

To also provide background information, respondents were requested to characterize, using a Likert scale, their research area across 12 disciplinary fields, and 4 knowledge characteristics (which in this paper are referred to as 'systemic', 'embodied', 'codified' and 'breakthroughs expected'). Respondents were then asked to identify what share of their research activities were basic, applied and development (following Mansfield, 1980;Kenney and Florida, 1994). Because the validity of such a 'Frascati-style' might be somewhat limited, we will report these outcomes as background information only; they are not part of our hypotheses. Finally, respondents were asked to identify the industry activity of their employer (for industrial researchers) or the industry with which they have most interaction (for university researchers). The sample of university researchers was constructed by collecting address information from all scientific staff at faculties in four selected disciplines: pharmaceutics and biotechnology, chemistry, mechanical engineering, and electrical engineering. In particular, respondents have been sought at two technical universities (Eindhoven University of Technology, Delft University of Technology) as well as three 
regular universities (Rijksuniversiteit Groningen, Universiteit Leiden, Universiteit Utrecht). A pilot study was conducted, and the final survey was sent out to 2082 staff members. We collected 575 valid responses. Performing a non-response analysis, we compared a number of distributional features with known features of the full population, and found the differences to be small. Full professors, associate professors and assistant professors are somewhat underrepresented in our sample (by approximately 20\%), while Ph.D. students are somewhat overrepresented (by approximately 20\%).

Similarly, the sample of industry researchers was aimed at selected sectors held exemplary in the Marsili and Pavitt taxonomies and recognised in the Netherlands (Marsili and Verspagen, 2002): pharmaceutical or biotechnology sector, chemical sector, machinery, basic and fabricated metal products, mechanics, and electrical and telecommunications equipment. Respondents were asked to indicate the sector they worked in. A small number indicated they worked in areas different from those described above and their questionnaires were discarded for the analysis. We selected industry researchers in three ways: Dutch individuals who were listed as inventors in EPO patents that were not owned by universities; Dutch authors of papers published in selected refereed journals for whom a non-university affiliation was given; members of the Royal Institution of Engineers in the Netherlands (KIVI NIRIA). The total sample amounted to 2088 and we received 422 valid responses. Our questionnaire to researchers at the industry side produced quite a homogeneous response across the sectors we aimed to study. An additional category called 'Other manufacturing' represents $9.7 \%$ of the sample and a category 'service sector' accounted for $2.4 \%$. Only $3.2 \%$ of the respondents indicated they did not work in any of the categories mentioned. 


\section{Background data on our respondents}

First, we provide some background data on our respondents, differentiating between the science-based and the development-based regime (Table 2). We observe that, on average, researchers in the science-based regime are older and have more papers published in refereed academic journals (in the four-years period preceding the survey). No significant differences are found for the number of researchers who are listed as inventors on a patent, or the number of researchers who had any personal involvement in a spin-off or a start-up business during the 10 years preceding the survey. If we split the university researchers and the industrial researchers, however, we find quite significant differences within the regimes (Table 3). On the whole, university researchers are significantly younger, have more papers and appear less often as inventors on patents. Table 4 presents the percentage of researchers who consider their work to be basic, applied or experimental. It also shows the significance of the MannWhitney T-test differences between the two regimes we distinguish.

[Table 2, 3 and 4 about here]

We find that in a science-based regime, the share of work that is considered to be basic research is approximately $50 \%$ for university researchers, compared to $15 \%$ for industrial researchers. In the development-based regime, basic research has a share of $32 \%$ at universities and $8 \%$ at firms (for more results see Table 4). Given such big differences, it comes as no surprise that the Mann-Whitney T-test differences are highly significant. Our findings confirm the expectation that, for the science-based regime, basic research is predominantly the domain of universities and hence technology transfer is likely to be mainly about outcomes of basic research. The major focus in a development-based regime is more on the creation and transfer of applied knowledge rather than on fundamental, scientific knowledge. 


\section{Empirical findings}

In this section we discuss in how far our empirical findings provide support for our hypotheses.

Hypotheses 1 and 2 specify the relative differences in the types of transfer mechanisms being employed in the two regimes. Hypothesis 1 predicts that 'Scientific publications, patent data and academic spin-offs are more important means of technology transfer in sciencebased regimes than in development-based regimes'. Table 5 presents our findings and provides information on the correlation coefficients for the significant Mann-Whitney T-test differences between the two regimes. As can be seen, the three mechanisms specified in the hypothesis are more important mechanisms for technology transfer in a science-based regime than for a development-based regime. So, Hypothesis 1 can be accepted. In addition, our findings indicate that consultancy by academic staff is also more important in a science-based regime. An explanation may be that this also forms a mechanism that, like academic spinoffs, supports the combined exchange of codified and tacit knowledge (Marsili, 2001). If we consider the overall ranking of the various channels (see Columns 2 and 3), though, we see relatively small differences only. We will come back to this in the discussion section. Hypothesis 2 predicts that 'Joint $R \& D$ collaborations, participation in conferences and in regional and/or professional networks, as well as inflow of PhD graduates are more important means of technology transfer in development-based regimes than in science-based regimes'. Again, all the specified mechanisms are found to be more important in a development-based regime than in a science-based regime. So also this hypothesis can be accepted. Apart from the differences that form the core of our hypotheses, it is worth emphasizing that for the remaining transfer mechanisms, differences are small and nonsignificant. In other words, apart from exhibiting relative differences, the two regimes also 
share a substantial number of similar transfer mechanisms. We also come back to this issue in the final section of our paper.

[Table 5, Table 6 and Table 7 about here]

Hypothesis 3 specifies three barriers that are expected to occur in both regimes, being information leakage (3a), conflict of interests (3b) and scientific knowledge being too general (3c). The first and third are - obviously - measured among the industrial researchers, whereas for the second item we measure among the academic researchers, as they are most likely to perceive a conflict of interest. Here, Table 6 and Table 7 demonstrate that all items show no significant differences between the two regimes that we distinguish. (For Hypothesis 3a, see Table 7 item $b$; for Hypothesis 3b, see Table 6 item $a$ and for Hypothesis 3 c, see Table 7 item c.). So, the three hypotheses claiming that all three barriers play a major role in both regimes can be accepted. In addition, we can conclude that conflict of interest (from perspective of academia) and information leakage (from perspective of industry) are considered to be the biggest barriers reported by our respondents.

Finally, Hypothesis 4a claims that, specifically in a science-based regime, a major barrier is formed by the high costs of managing joint research projects. We measured this among industrial researchers and, as shown in Table 7 (item a), this can indeed be confirmed and its relevance is significantly higher for a science-based regime than for a development-based one. Similarly, university researchers acknowledge that technology transfer activities involve high costs and time to the university (Table 6, item f). Finally, we can also accept Hypothesis 4b stating that in a development-based regime, a major barrier is the lack of application-readiness of scientific knowledge (see Table 7, item g). Because knowledge is considered to be more general, industrial researchers in development-based regimes also report that knowledge is 
difficult to locate (Table 7, item e). Although we must note that these barriers are not among the most important ones, they are indeed relatively more important for a development-based regime.

\section{Discussion and Conclusions}

Whereas the general innovation literature until now has stressed the differentiated nature of the contribution of academic research to industrial innovation (Nelson and Winter, 1982; Breschi et al, 2000), there are still relatively few empirical insights into the degree in which technology transfer processes differ across industrial sectors. To address this, the purpose of this paper is to determine the extent in which technology transfer processes differ across industries and whether these differences are only minor or possibly very substantial. Based on the distinction between a science-based regime and a development-based regime, we have analysed the extent to which are differences in the mechanisms of technology transfer employed and barriers inhibiting the transfer process.

A first key finding is that the two regimes exhibit a number of relative differences regarding the type of transfer mechanisms being employed. In a science-based regime, scientific publications, patent texts, academic spin-offs and consultancy by academic staff are relatively more important than in a development-based regime. Whereas in the latter, joint R\&D programs, participation in conferences, regional and/or professional networks and inflow of $\mathrm{PhD}$ graduates are relatively more important, when compared to the former. $\mathrm{A}$ second key finding is that despite these relative differences, both regimes also share a number of similarities regarding the type of mechanism for technology transfer. Both regimes exhibit a similar use and importance of personal and informal contacts, flows of undergraduate students (B.Sc. or M.Sc. level), mutual exchange of staff (permanent and temporary), sharing facilities and contract research. Our results show that in both regimes the mechanisms of 
knowledge transfer that are among the 10 most heavily-used as well as among the 6 least-used are almost the same. A third key finding is that both regimes are also largely similar regarding major barriers inhibiting the process, formed by risks of information leakage, conflicts of interests as well as by scientific knowledge being too general. Relative differences regarding barriers are limited to the high costs of managing joint research projects in a science-based regime and the risk of scientific knowledge being too theoretical to be useful for firms.

So, an important conclusion from our study is that although technology transfer processes in science-based and technology-based industries each have certain specificities, they also have a lot in common regarding the use of transfer mechanisms as well as their major barriers. This is an important conclusion that contributes to the literature in the following way. Most studies until have emphasized the highly idiosyncratic nature of technology transfer processes and considered how the specific properties of technology transfer vary from one process to another (Bonaccorsi and Piccaluga, 1994; D'Este and Patel, 2007). Another issue that emerges from the literature is that that most studies have especially focused on the role of one-directional and/or formal mechanisms such as patents, spinoffs, licenses and publications (e.g. Shane 2004; Link et al., 2003; Jensen et al., 2003), but have neglected the role of bidirectional and/or informal mechanisms (Arundel and Geuna, 2004; D’Este and Patel, 2007). When predominantly considering the role of formal and/or one-directional mechanisms, our findings do indicate that the largest differences between both patterns are to be found here as well, in line with most studies until now. However, when considering a more comprehensive set of transfer mechanisms, including different types of informal and/or bidirectional mechanisms, the overall picture that emerges from our findings is not only that these differences move to the background and are more relative than absolute, but also that there is a remarkable degree of similarity among transfer mechanisms. Seen in this way, it comes as no surprise that barriers inhibiting the use of these transfer mechanisms are then also more 
similar than different. In this way our study makes an important contribution to the literature by showing that when one keeps a focus on the role of formal and/or one-directional mechanisms, one keeps seeing more differences than similarities. However, when broadening the focus by also including the role of other (more informal and/or bi-directional) mechanisms, similarities between technology transfer processes come much stronger to the foreground. So, whereas our findings are in line with the idea of heterogeneity in technology transfer processes as emphasized in most studies until now, we demonstrate that, regarding facilitating transfer mechanisms and inhibiting barriers, these processes have much more in common than that they differ and than what has been previously assumed.

These findings have implications for public policy, which considers technology transfer as a key area within the broader domain of innovation policy (OECD, 2003; Dosi et al., 2006; European Commission, 2008). Despite some relative differences between both regimes, the substantial degree of similarity does not seem to justify a policy approach that explicitly focuses on diversity among technology transfer processes. Based on our findings, concerns that policy would possibly ignore too much the role of diversity (e.g. Metcalfe, 1995; Nowotny et al., 2001; Tödtling and Trippl, 2005), seem to be unnecessary. Our findings suggest that policy that contributes most to the transfer process is formed by a more generic policy approach that covers a wide range of transfer mechanisms and addresses the major barriers, regardless of specific industries. In addition, such a more generic policy approach offers the requisite freedom for practitioners and lowers the potential risk of government failure that may be associated with specific, targeted policy instruments (Metcalfe, 1995; Dosi et al., 2006). Furthermore, given its fit with both a science-based and development-based regime, this generic policy approach may also be a potentially attractive, alternative approach to the typically US-based, IP-focused technology transfer model that overly focuses on a science-based regime but pays insufficient attention to a development-based regime (e.g. 
Litan et al., 2007; Kenney and Patton, 2009). In this way, our study may inform the policy debate by suggesting an alternative policy approach that may have been undervalued until now (Berman, 2008; Kenney and Patton, 2009; Ponomariov and Boardman, 2008; Boardman and Ponomariov, 2009).

\section{Limitations and future research}

Given the nature of our study, some limitations must be taken into account. First, there might be a bias induced by the sample selection. We selected respondents in specific industries and related academic disciplines. As a result, other industries may have be somewhat underrepresented to the extent that these might carry different features. This study has focused on the perspectives of researchers that actually perform $R \& D$ activities. As a consequence, technology transfer to firms without their own in-house R\&D is not covered. A survey focusing on all types of firms, as the CIS survey has done, may possibly find a lower share of respondents that use all the mechanisms surveyed and a potentially higher rating of (some of) the barriers. Issues for future research are as follows. First, future research could examine in how far our findings are generalizable to other countries. Although it has been suggested that regimes of technological innovation are remarkably similar across countries (Breschi et al., 2000), it remains an under addressed issue in how far this is also the case for technology transfer regimes (Decter et al., 2007). As argued above, there may be national, cultural or policy factors that affect the use of technology transfer mechanisms. Future research could verify this. Particularly a multi-country approach could be useful. Second, this study did not address potential diversity within the country. Future studies may consider how much practitioners may be supported or constrained by their institutional environment such as university or departmental policy for academic researchers, and corporate or business unit strategy for industrial researchers. 


\section{References}

Arundel, A., Van de Paal, G., Soete, L., 1995. PACE Report: Innovation Strategies of Europe's Largest Firms: Results of the PACE Survey for Information Sources, Public Research, Protection of Innovations, and Government Programmes. Final Report, MERIT, University of Limburg, Maastricht.

Arundel, A., Geuna A., 2004. Proximity and the use of public science by innovative firms European firms. Economics of Innovation and New Technology (13), $559-580$.

Azagra-Caro, J.M., 2007. What type of faculty member interacts with what type of firm? Some reasons for the delocalisation of university-industry interaction. Technovation 27 (11), 704-715.

Balconi, M., Laboranti, A., 2006. University-industry interactions in applied research: the case of microelectronics. Research Policy 35 (10), 1616-1630.

Bekkers, R., BodasFreitas, I.M., 2008. Analyzing technology transfer channels between universities and industry: to what degree do sectors also matter? Research Policy 37 (10), 1837-1853.

Bercovitz, J., Feldman, M., 2006. Entrepreneurial universities and technology transfer: a conceptual framework for understanding knowledge-based economic development. Journal of Technology Transfer 31 (1), 175 - 188.

Berman, E.P., 2008. Why did universities start patenting? Institution-building and the road to the Bayh-Dole Act. Social Studies of Science 38 (6), 835-871.

Boardman, P.C., 2008. Beyond the stars: the impact of affiliation with university biotechnology centers on the industrial involvement of university scientists. Technovation 28 (5), 291-297.

Boardman, P.C., Ponomariov, B.L., 2009. University researchers working with private companies. Technovation 29 (2), 142-153.

Bonaccorsi, A., Piccaluga, A., 1994. A theoretical framework for the evaluation of university-industry relationships. R\&D Management 24 (3), 229-247.

Breschi, S., Malerba, F., Orsenigo, L., 2000. Technological regimes and Schumpeterian patterns of innovation. The Economic Journal 110 (463), 388-410.

Calderini, M., Franzoni, C., Vezzulli, A., 2007. If star scientists do not patent: the effect of productivity, basicness and impact on the decision to patent in the academic world. Research Policy 36 (3), 303-319. 
Cohen, W.M., Levinthal, D.A., 1990. Absorptive capacity: a new perspective on learning and innovation. Administrative Science Quarterly 35 (1), 128-152.

Cohen,W.M., Nelson, R.R., Walsh, J.P., 2002. Links and impacts: the influence of public research on industrial R\&D. Management Science 48 (1), 1-23.

Coriat, B., Weinstein, O., 2001. The organization of R\&D and the dynamics of innovation. Asectoral view.European Sectoral Systems of Innovation (ESSY) Working Paper. http://www.cespri.unibocconi.it/essy/wpapers.htm.

Coriat, B., Orsi, F., Weinstein, O., 2003. Does biotech reflect a new science-based innovation regime? Industry and Innovation 10 (3), 231-253.

Decter, M., Bennett, D., Leseure, M., 2007. University to business technology transfer - UK and USA comparisons. Technovation 27 (3), 145-155.

D'Este, P., Patel, P., 2007. University-industry linkages in the UK: what are the factors underlying the variety of interactions with industry? Research Policy 36(9), 1295-1313.

DiGregorio, D., Shane, S., 2003. Why do some universities generate more start-ups than others? Research Policy 32 (2), 209-227.

Dosi, G., Llerena, P., SylosLabini, M., 2006. The relationship between science, technologies and their industrial exploitation: an illustration through the myths and realities of the so-called 'European Paradox’. Research Policy 35 (10), 1450-1464.

European Commission, 2008. The governance challenges for knowledge policies in the Lisbon Strategy: between revolution and illusion. EUR 23469. European Commission, DG Research, Brussels. 43pp.

Fontana, R., Geuna, A., Matt, M., 2006. Factors affecting university-industry R\&D projects: the importance of searching, screening and signalling. Research Policy 35 (2), 309-323.

Gilsing, V.A., Burg, E. van, Romme, A.G.L., 2010. Policy principles for the creation and success of corporate and academic spin-offs. Technovation30 (1), 12-23.

Gilsing, V.A., Nooteboom, B., 2006. Exploration and exploitation in innovation systems: the case of pharmaceutical biotechnology. Research Policy 35 (1), 1-23.

Giuri, P., Mariani., M., Brusoni, S., Crespi, G., Francoz, D., Gambardella, A., Garcia-Fontes, W., Geuna, A., Gonzales, R., Harhoff, D., Hoisl, K., Le Bas, C., Luzzi, A., Magazzini, L., Nesta, L., 
Nomaler, O., Palomeras, N., Patel, P., Romanelli M., Verspagen, B., 2007. Inventors and invention processes in Europe: Results from the PatVal-EU survey. Research Policy. 36, 1107-1127.

Jensen, R., Thursby, J.G., Thursby M.C., 2003. The disclosure and licensing of university inventions: the best way we can do with the $\mathrm{s}^{* *} \mathrm{t}$ we get to work with. International Journal of Industrial Organization (21), $1271-1300$.

Kenney, M., Florida, R., 1994. The organization and geography of Japanese R\&D: results from a survey of Japanese electronics and biotechnology firms. Research Policy 23 (3), 305-322.

Kenney, M., Patton, D., 2009. Reconsidering the Bayh-Dole Act and the current university ownership model. Research Policy 38 (9), 1407-1422.

Koumpis, K., Pavitt, K., 1999. Corporate activities in speech recognition and natural language: another 'new science'-based technology. International Journal of Innovation Management 3 (3), 335-366.

Krabel, S., Mueller, P., 2009. What drives scientists to start their own company? An empirical investigation of Max Planck Society scientists. Research Policy 38 (6), 947-956.

Lin, J.L., Fang, S.C., Fang, S.R., Tsai, F.S., 2009. Network embeddedness and technology transfer performance in R\&D consortia in Taiwan. Technovation 29 (11), 763-774.

Link, A.N., Scott, J.T. and Siegel, D.S., 2003. The economics of intellectual property at universities: an overview of the special issue. International Journal of Industrial Organisation (21), 1217 - 1225.

Litan, R.E., Mitchell, L., Reedy, E.J., 2007. Commercializing university innovations: alternative approaches. In: Jaffe, A.B., Lerner, J., Stern, S. (Eds.), Innovation Policy and the Economy, vol. 8. University of Chicago Press, Chicago, pp.31-58.

Mansfield, E., 1980. Basic research and productivity increase in manufacturing. The American Economic Review 70 (5), 863-873.

Marsili, O., 2001. The Anatomy and Evolution of Industries: Technical Change and Industrial Dynamics. Edward Elgar Publishing Ltd, Cheltenham.

Marsili,O., Verspagen, B., 2002. Technology and dynamics of industrial structures: an empirical mapping of Dutch manufacturing. Industrial and Corporate Change 11 (4), 791-815.

Martin, F., 1998. The economic impact of Canadian university R\&D. Research Policy 27 (7), 677-687.

McMillan, G.S., Narin, F., Deeds, D.L., 2000. An analysis of the critical role of public science in innovation: the case of biotechnology. Research Policy 29 (1), 1-8. 
Metcalfe, J.S., 1995. Technology systems and technology policy in an evolutionary framework.

Cambridge Journal of Economics 19 (1), 25-46.

Nelson, R.R., Winter, S.G., 1982. An Evolutionary Theory of Economic Change. Harvard University

Press, Cambridge.

Nikulainen, T., Palmberg, C., 2010. Transferring science-based technologies to industry - does nanotechnology make a difference? Technovation 30 (1), 3-11.

Nowotny, H., Scott, P., Gibbons, M., 2001. Re-thinking Science. Knowledge and the Public in an Age of Uncertainty. Polity Press, Cambridge.

OECD, 2003. Turning Science into Business. Patenting and Licensing at Public Research

Organizations, OECD Publications, Paris.

Pavitt, K., 1984. Sectoral patterns of technical change: towards a taxonomy and a theory. Research Policy 13 (6), 343-373.

Peneder, M., 2008. The problem of private under-investment in innovation: a policy mind map. Technovation 28 (8), 518-530.

Ponomariov, B., Boardman, P.C., 2008. The effect of informal industry contacts on the time university scientists allocate to collaborative research with industry. The Journal of Technology Transfer 33 (3), $301-313$.

Porter, M.E., 1990. The Competitive Advantage of Nations. MacMillan Press, London.

Rasmussen E., 2008. Government instruments to support the commercialization of university research: lessons from Canada. Technovation 28 (8), 506-517.

Salter, A. J., \& Martin, B. R. (2001). The economic benefits of publicly funded basic research: a critical review. Research Policy, 30(3), 509-532.

Shane, S. 2004. Academic entrepreneurship. University spin-offs and wealth creation. Edward Elgar, Cheltenham (UK).

Swann, G. M. P., 2002. Innovative Businesses and the Science and Technology Base: an analysis using CIS3 data Report for the Department of Trade and Industry. DTI, London, UK.

Teece, D.J., 1986. Profiting from technological innovation: implications for integration, collaboration, licensing and public policy. Research Policy 15 (6), 285-305. 
Tödtling, F., Trippl, M., 2005. One size fits all? Towards a differentiated regional innovation policy approach. Research Policy 34 (8), 1203-1219.

Vanhaverbeke, W., Gilsing, V., Beerkens, B., Duysters, G., 2009. The role of alliance network redundancy in the creation of core and non-core technologies. Journal of Management Studies 46 (2), 215-244.

Verspagen, B., 2006. University research, intellectual property rights and European innovation systems. Journal of Economic Surveys 20 (4), 607-632.

Welsh, R., Glenna, L., Lacy, W., Biscotti, D., 2008. Close enough but not too far: assessing the effects of university-industry research relationships and the rise of academic capitalism. Research Policy 37 (10), 1854-1864.

Yusuf, S., 2008. Intermediating knowledge exchange between universities and business. Research Policy 37 (8), 1167-1174. 
Tables and Figures

Table 1: Taxonomy of two different types of technology transfer regimes

\begin{tabular}{|l|c|c|c|c|c|}
\hline & \multicolumn{2}{|c|}{$\begin{array}{c}\text { (A) Key characteristics of knowledge } \\
\text { and its importance to industry }\end{array}$} & \multicolumn{2}{c|}{$\begin{array}{c}\text { (B) Key characteristics of } \\
\text { the transfer process }\end{array}$} \\
\hline & $\begin{array}{c}\text { (1) Degree of } \\
\text { differentiation of } \\
\text { knowledge base }\end{array}$ & $\begin{array}{c}\text { (2) Nature } \\
\text { of scientific } \\
\text { knowledge }\end{array}$ & $\begin{array}{c}\text { (3) Importance of } \\
\text { scientificknowledge } \\
\text { to industry }\end{array}$ & $\begin{array}{c}\text { (4) Intensity } \\
\text { of interaction }\end{array}$ & $\begin{array}{c}\text { (5) Dominant } \\
\text { mechanisms } \\
\text { employed }\end{array}$ \\
\hline $\begin{array}{l}\text { Science-based } \\
\text { regimes }\end{array}$ & $\begin{array}{c}\text { Low } \\
\text { ('stand-alone } \\
\text { knowledge'; relatively } \\
\text { independent pieces of } \\
\text { knowledge) }\end{array}$ & $\begin{array}{c}\text { Basic } \\
\text { knowledge }\end{array}$ & $\begin{array}{c}\text { High to } \\
\text { Very high }\end{array}$ & $\begin{array}{c}\text { Low to } \\
\text { medium } \\
\text { (division-of- } \\
\text { labour model) }\end{array}$ & $\begin{array}{l}\text { Publications } \\
\text { Patents } \\
\text { Consultancy } \\
\text { Spin-offs }\end{array}$ \\
\hline $\begin{array}{l}\text { Development- } \\
\text { based regimes }\end{array}$ & $\begin{array}{c}\text { High } \\
\text { 'systemic knowledge'; } \\
\text { relatively } \\
\text { interdependent pieces } \\
\text { of knowledge) }\end{array}$ & $\begin{array}{c}\text { Applied } \\
\text { knowledge }\end{array}$ & Low to Medium & $\begin{array}{c}\text { Medium } \\
\text { To high } \\
\text { (participation } \\
\text { in application) }\end{array}$ & $\begin{array}{l}\text { Joint R\&D Programs } \\
\text { Participation in } \\
\text { conferences } \\
\text { Regional/professional } \\
\text { networks } \\
\text { Inflow of PhD graduates }\end{array}$ \\
\hline
\end{tabular}

Table 2: Individual characteristics of the surveyed researchers

\begin{tabular}{|l|c|c|c|}
\hline Individual characteristics & Science-based regime & Development-based regime & Test \\
\hline Age & 43.28 & 41.67 & $3.58^{*}$ \\
\hline Number of authored papers & 2.70 & 2.48 & $5.08^{* *}$ \\
\hline $\begin{array}{l}\text { Number of patents where listed as } \\
\text { inventor }\end{array}$ & 2.09 & 2.10 & 0.00 \\
\hline Spin-off founder & 0.12 & 0.09 & 1.54 \\
\hline Start-up founder & 0.11 & 0.09 & 0.55 \\
\hline
\end{tabular}

Note: the values for patents and for papers are coded as follows: (1) one, (2) two or three, (3) five to ten, (4) more than ten.

Table 3: Individual characteristics of the surveyed researchers

\begin{tabular}{|l|c|c|c|c|c|c|c|c|}
\hline & \multicolumn{3}{|c|}{ Science-based regime } & \multicolumn{2}{c|}{ Development-based regime } & \multicolumn{2}{c|}{$\begin{array}{c}\text { Test difference } \\
\text { between regimes }\end{array}$} \\
\hline $\begin{array}{l}\text { Individual } \\
\text { characteristics }\end{array}$ & Industrial & University & Test & Industrial & University & Test & University & Industry \\
\hline Age & 48.5 & 38.7 & $63.44 * * *$ & 47.2 & 37.5 & $76.57 * * *$ & 0.74 & 1.331 \\
\hline $\begin{array}{l}\text { Number of authored } \\
\text { papers }\end{array}$ & 2.5 & 2.8 & $4.39 * *$ & 2.3 & 2.6 & $5.5 * * *$ & $2.99 *$ & $3.47 *$ \\
\hline $\begin{array}{l}\text { Number of patents } \\
\text { where listed as } \\
\text { inventor }\end{array}$ & 2.3 & 1.7 & $14.33^{* * *}$ & 2.3 & 1.6 & $24.71^{* * *}$ & 0.99 & 0.522 \\
\hline Spin-off founder & 0.1 & 0.1 & 2.354667 & 0.1 & 0.1 & $4.28^{* *}$ & 1.28 & 0.338 \\
\hline Start-up founder & 0.2 & 0.1 & $7.67 * * *$ & 0.1 & 0.1 & 2.309 & 0.06 & 1.134 \\
\hline
\end{tabular}

\footnotetext{
${ }^{1}$ Relatively independent pieces of knowledge.
} 
Table 4: Basic, applied and experimental knowledge

\begin{tabular}{|l|c|c|c|c|c|c|c|c|}
\hline & \multicolumn{3}{|c|}{ Science-based regime } & \multicolumn{2}{c|}{ Development-based regime } & \multicolumn{2}{c|}{$\begin{array}{c}\text { Test difference between } \\
\text { regimes }\end{array}$} \\
\hline $\begin{array}{l}\text { Form of knowledge } \\
\text { transfer from universities } \\
\text { to firms }\end{array}$ & Industrial & University & Test & Industrial & University & Test & University & Industry \\
\hline$\%$ basic research & $14.86 \%$ & $49.86 \%$ & $89.6^{* * *}$ & $8.33 \%$ & $31.7 \%$ & $80.13^{* * *}$ & $27.39^{* * *}$ & $9.3 * * *$ \\
\hline$\%$ applied research & $60.95 \%$ & $39.44 \%$ & $40.24^{* * *}$ & $54.28 \%$ & $50.8 \%$ & 1.77 & $16.74^{* * *}$ & $5.56^{* *}$ \\
\hline$\%$ experimental research & $22.93 \%$ & $11.48 \%$ & $25.9^{* * *}$ & $36.83 \%$ & $0.0 \%$ & $52.16^{* * *}$ & $13.47^{* * *}$ & $26.76^{* * *}$ \\
\hline
\end{tabular}

Table 5: Importance rating for the surveyed knowledge transfer (scale 1-4)

\begin{tabular}{|c|c|c|c|}
\hline Form of knowledge transfer from universities to firms & $\begin{array}{l}\text { Science-based } \\
\text { regime }\end{array}$ & $\begin{array}{l}\text { Development- } \\
\text { based regime }\end{array}$ & $\begin{array}{c}\text { Test difference } \\
\text { between regimes }\end{array}$ \\
\hline Scientific publications in (refereed) journals or books & 3.49 & 3.19 & $2.44 * * *$ \\
\hline Personal (informal) contacts & 3.22 & 3.21 & 0.00 \\
\hline $\begin{array}{l}\text { Patent texts, as found in the patent office or in patent } \\
\text { databases }\end{array}$ & 3.21 & 3.03 & $9.65^{* * *}$ \\
\hline Students working as trainees & 3.20 & 3.18 & 0.00 \\
\hline $\begin{array}{l}\text { Other publications, including professional publications and } \\
\text { reports }\end{array}$ & 3.01 & 2.99 & 0.11 \\
\hline Staff holding positions in both a university and a business & 3.00 & 3.10 & 2.42 \\
\hline $\begin{array}{l}\text { Joint R\&D projects (except those in the context of EU } \\
\text { Framework Programmes) }\end{array}$ & 2.93 & 3.11 & $10.6^{* * *}$ \\
\hline $\begin{array}{l}\text { Sharing facilities (e.g. laboratories, equipment, housing) with } \\
\text { universities }\end{array}$ & 2.86 & 2.91 & 0.66 \\
\hline Licenses of university-held patents and 'know-how' licenses & 2.82 & 2.94 & $3.15^{*}$ \\
\hline University spin-offs (as a source of knowledge) & 2.82 & 2.64 & $6.56^{* * * *}$ \\
\hline Participation in conferences and workshops & 2.74 & 2.85 & $3.82 * *$ \\
\hline Contract research (excl. Ph.D. projects) & 2.64 & 2.69 & 0.68 \\
\hline $\begin{array}{l}\text { Flow of university staff members to industry positions (exc. } \\
\text { Ph.D. graduates) }\end{array}$ & 2.64 & 2.67 & 0.04 \\
\hline Temporary staff exchange (e.g. staff mobility programmes) & 2.57 & 2.48 & 2.01 \\
\hline $\begin{array}{l}\text { Joint R\&D projects in the context of EU Framework } \\
\text { Programmes }\end{array}$ & 2.56 & 2.48 & 1.66 \\
\hline $\begin{array}{l}\text { Specific knowledge transfer activities organised by the } \\
\text { university's TTO }\end{array}$ & 2.51 & 2.47 & 0.54 \\
\hline Personal contacts via alumni organizations & 2.51 & 2.53 & 0.02 \\
\hline Financing of Ph.D. projects & 2.46 & 2.50 & 0.33 \\
\hline Consultancy by university staff members & 2.43 & 2.29 & $4.51 * *$ \\
\hline University graduates as employees (B.Sc. or M.Sc. level) & 2.40 & 2.37 & 0.53 \\
\hline $\begin{array}{l}\text { Personal contacts via membership of professional } \\
\text { organisations (e.g. KIVI NIRIA) }\end{array}$ & 2.14 & 2.27 & $3.43^{*}$ \\
\hline $\begin{array}{l}\text { Contract-based in-business education and training delivered } \\
\text { by universities }\end{array}$ & 2.12 & 2.20 & 1.15 \\
\hline University graduates as employees (Ph.D. level) & 1.92 & 2.09 & $7.05^{* * * *}$ \\
\hline Total Average & 2.74 & 2.76 & $\mathbf{0 . 0 2}$ \\
\hline
\end{tabular}

Note: respondents who indicated they did not use a specific channel were excluded for calculating these averages. Values range from 1 ('of very little importance') to 4 ('very important'). 
Table 6: Barriers identified by university researchers

\begin{tabular}{|l|c|c|c|}
\hline & $\begin{array}{c}\text { Science-based } \\
\text { regime }\end{array}$ & $\begin{array}{c}\text { Development- } \\
\text { based regime }\end{array}$ & $\begin{array}{c}\text { Test difference } \\
\text { between regimes }\end{array}$ \\
\hline $\begin{array}{l}\text { a. Joint R\&D is hindered by conflicts between academic researcher who } \\
\text { want to publish research and commercial researchers who want to } \\
\text { patent research }\end{array}$ & 2.72 & 2.64 & 1.19 \\
\hline b. It is hard to find appropriate industrial partners for joint R\&D projects & 2.67 & 2.63 & 0.15 \\
\hline $\begin{array}{l}\text { c. Companies do not want to cooperate on R\&D with universities; they } \\
\text { just want to absorb our knowledge }\end{array}$ & 2.65 & 2.57 & 0.63 \\
\hline $\begin{array}{l}\text { d. } \text { Cooperation with the industry is hindered by cultural differences } \\
\text { between academic and commercial researchers }\end{array}$ & 2.55 & 2.51 & 0.36 \\
\hline $\begin{array}{l}\text { e. Transferring knowledge to the industry is too costly for universities } \\
\text { (either in terms of money of time) }\end{array}$ & 2.47 & 2.22 & $10.10^{* * * *}$ \\
\hline $\begin{array}{l}\text { f. Universities are not willing to spend time and money in transferring } \\
\text { their knowledge to industry }\end{array}$ & 2.42 & 2.19 & $8.08^{* * *}$ \\
\hline $\begin{array}{l}\text { g. Conducting contract research only results in more income for our } \\
\text { research group. We do not learn anything from conducting such } \\
\text { research }\end{array}$ & 2.35 & 2.11 & $7.72^{* * *}$ \\
\hline $\begin{array}{l}\text { h. The industry is not interested in the knowledge developed at the } \\
\text { university }\end{array}$ & 1.98 & 2.07 & 1.11 \\
\hline
\end{tabular}

Table 7: Barriers identified by industrial researchers

\begin{tabular}{|l|c|c|c|}
\hline & $\begin{array}{c}\text { Science-based } \\
\text { regime }\end{array}$ & $\begin{array}{c}\text { Development- } \\
\text { based regime }\end{array}$ & $\begin{array}{c}\text { Test difference } \\
\text { between regimes }\end{array}$ \\
\hline $\begin{array}{l}\text { a. Joint research projects with universities or PROs are difficult to } \\
\text { manage and/or involve high overhead costs }\end{array}$ & 2.70 & 2.54 & $2.78^{*}$ \\
\hline $\begin{array}{l}\text { b. The results of joint research projects with universities or PROs imply a } \\
\text { significant risk of leaks to competitors }\end{array}$ & 2.33 & 2.30 & 0.26 \\
\hline $\begin{array}{l}\text { c. Knowledge developed in universities and PROs is too general to } \\
\text { address our specific knowledge needs }\end{array}$ & 2.29 & 2.40 & 1.84 \\
\hline $\begin{array}{l}\text { d. Being involved in the application of knowledge developed in } \\
\text { universities or PROs is too costly (either in terms of time or money) }\end{array}$ & 2.27 & 2.35 & 8.24 \\
\hline $\begin{array}{l}\text { e. Relevant knowledge developed in universities and PROs is difficult to } \\
\text { locate (e.g., finding the right publications or people) }\end{array}$ & 2.24 & 2.49 & $8.78^{* * *}$ \\
\hline $\begin{array}{l}\text { f. Researchers working in universities or PROs do not fit in well with our } \\
\text { corporate culture }\end{array}$ & 2.24 & 2.29 & 0.09 \\
\hline $\begin{array}{l}\text { g. Knowledge developed in universities and PROs is too theoretic to be } \\
\text { useful in our particular case }\end{array}$ & 2.12 & 2.32 & $5.35^{* *}$ \\
\hline
\end{tabular}

